\title{
Limb Associated Lesion Identification
}

National Cancer Institute

\section{Source}

National Cancer Institute. Limb Associated Lesion Identification. NCI Thesaurus. Code C119568.

The identification of the limb that contains a non-neoplastic or neoplastic pathologic process. 